\title{
A Review Study on the Marriage and Relationship Research in Turkey
}

\author{
Sevgi Güney \\ Clinical Psychologist, Ankara University, Ankara, Turkey. \\ Email: sevgiguney@gmail.com \\ Received April 30 ${ }^{\text {th }}, 2011$; revised June $6^{\text {th }}, 2011$; accepted July $8^{\text {th }}, 2011$.
}

\begin{abstract}
The aim of this study is to examine the studies on marriage and relationship in Turkey.127 studies ( 82 research studies and 45 scale studies) published and unpublished between 1997-2008 were examined toprovide an overview for professionals about the marriage and relationship research done in Turkey. The studies were reviewed in terms of their general characteristics, conceptual frameworks and methods of investigation. The results were discussed and suggestions were given in terms of future directions.
\end{abstract}

Keywords: Meta Analytical Review, Marriage, Relationship Research

\section{Introduction}

There is a growing body of research findings indicating that psychopathology is linked with marital and intimate relationship functioning (Whisman \& Uebelacker, 2003; Macnab, 1999). In additional to marriage and relationship functioning, culture is another crucial factor in understanding the nature of the marital relationships and its perceived satisfaction (Sahin \& Sahin, 1992; Fisiloglu \& Demir, 2000). For example, Fisiloglu et al. (2008) indicated that the vast majority of individuals in North America choose their own spouses and do so on the basis of love and personal affinity. Cherlin (2003) suggested that Australians place strong emphasis on personal choice, individual satisfaction and romantic love as the basis for marital commitment. In contrast, Fisiloglu and Kurter (2004) commented that marriages in many countries, such as Turkey, are frequently or even predominantly arranged. Again Kagitcibasi and Ataca (2005) stated that the dominant value in the system is honor, which is maintained to a large extent through men having control over the sexual behavior (chastity) of the women in the family. Through the relevant literature it is obvious that there is a link between relationship functioning and psychopathology. Gaining an overview of the research on marriage and relationship functioning may enable us to form an opinion regarding what has been done in the area. This can provide mental health professionals with the knowledge to improve intervention methods in the preventive mental health area.

The main objective of this study is to present the studies on marriage and relationship counseling and therapy in Turkey by examining and analyzing the studies' main criteria. The detailed aims of this study are 1) to review the relevant literature, 2 ) to determine what kinds of studies have been conducted in the area, 3) to ascertain the goals of the studies, 4) to formulate an opinion about the nature of the potential moderators in the studies examined.

\section{Scope}

According to the objectives of the study, a total of 127 studies were subjected to analysis. These included published and unpublished studies on marriage and relationship research projects in Turkey.

\section{Procedure}

The inclusion criteria was the studies conducted between 1997 and 2008 with keywords "marriage and relationship Turkey". The following methods were used to locate studies for inclusion of publish studies; computerized search of SAGE, ProQuest health and Medical Complete Data Base, EBSCOHOST Web Turkish, PsychINFO, MEDLINE, Psychology and Behaviour Sciences Collections, Master File Premier, PsychARTICLES, ERIC, Google Scholar in Turkey, Turkish Journal of Psychology, Turkish psychological Articles, Turkish Psychological Bulletin, 3P: Psychiatry, Psychology and Psychopharmacology, kris dergisi (Crisis Journal), Turkish Psychiatry Index. To locate unpublished studies for the inclusion two methods were used:

1) A computerized search of the Turkish Higher Education Documentation Center Library and The Middle East technical University Library.

2) A manual search of Master Theses and Dissertations in the Middle East Technical University Library.

\section{Coding}

A coding form was developed by the researcher. To summarize the reached studies and to constitute the potential moderator variables for future meta-analytic research, the studies were coded under the 2 main headings as A. Research Studies (RS) and B. Scale Studies (SS). The intimate relationships in coding form were used to subsume both marital and intimate relationships. Research Studies (RS) consists of mainly 4 categories. 1) Characteristics of The Research Studies (RS) with the three 
subcategories as the distribution, the publication status and the types; 2) The Aims of The Studies of Researchers; 3) Sample Characteristics with the subcategories as the sampling method, the mean age, the education level, the sample size, the marital status of the subjects in the samples, the duration of the relationships of the subjects in the samples, the living area of the subjects of the samples; 4) Researchers Characteristics with the subcategories as the status of the researchers, the gender of the researchers. Scale Studies (SS) consists of mainly 2 cate- gories. These are 1) Characteristics of Scale Studies with the subcategories as "Adapted OR Developed", Number of items in the Scale Studies "Nitems", Construct Validity Measures of the Scale Studies "Factor Structures", Reliability Measure of the Scale Studies "Cronbachalpha values", the scaling types of the scales in the Scale Studies and 2) The Type of The Scale Studies.

As a result of searching and coding procedures, 127 studies (82 research and 45 scale studies) were identified.

\section{Research Studies}

\section{Characteristics of the Research Studies}

\section{The Distribution}

Of the total 82 research studies (RS) dating from the 19972008 period, 23 (28\%) were conducted between 2005 and 2006, $20(24.3 \%)$ were in $2007-2008,15(18.3 \%)$ RS in 2001-2002, $11(13.4 \%)$ RS from 2003 to 2004 and 10 (12.4\%) RS in 19992000 period were conducted. The minimum number was made between 1997and 1998 with only 3 studies (3.6\%).

\section{The Publication Status}

$47(57.3 \%)$ studies were in a reviewed journals. $22(26.8 \%)$ studies were master theses, $6(7.4 \%)$ were $\mathrm{PhD}$ dissertations and $7(8.5 \%)$ studies were presented at meetings and/or conferences. Therefore the 35 (42.7\%) studies were unpublished research.

\section{The Types}

The research studies were categorized under 7 headings, cross-cultural research, descriptive research, comparitive research, descriptive and comparative research, experimental studies, longitudinal research and preliminary report. Most of them (46 studies $(56.5 \%)$ ) were classified into the descriptive research category. Comparative studies with descriptive methods were in the second with 12 studies (14.6\%). The number of experimental research with control group was 11 studies (13.4\%). Then cross-cultural research with 6 studies $(7.2 \%)$, comparative research with 4 studies $(4.7 \%)$, longitudinal research with 2 studies $(2.4 \%)$, and finally preliminary report with 1 study $(1.2 \%)$ were followed.

\section{The Aims of Studies of Researchers}

The category corresponds to five groups;

The Aims of the Researchers sub-category were collected into five groups; 1) The studies has been designed to display the marital adjustment (45 studies 54.9\%), 2) The studies designed to explore the nature of relationships (17 studies, $20.7 \%$ ), 3) The studies designed to show the marital satisfaction (11 studies, $13.4 \%)$, 4) The studies designed to people's attitudes towards intimate relationships (5 studies, 6.1\%), 5) The studies designed to reveal the cross-cultural differences on marital relationships (4 studies, 4.9\%) (Figure 1).

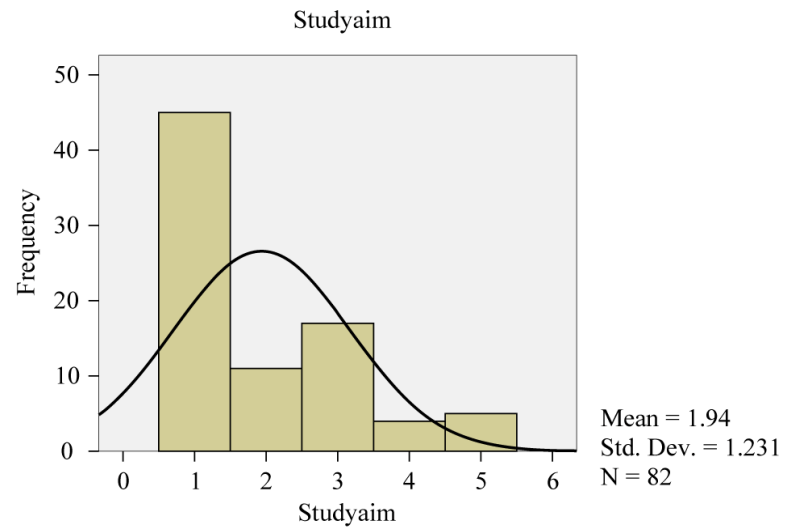

Figure 1.

The aims of the studies. 1) Marital Adjustment; 2) Descriptive studies on the nature of the relationships; 3) Marital Satisfaction; 4) Attitudes for intimate relationships; 5) Cross-cultural studies.

\section{Samples Characteristics}

\section{The Sampling Method}

Four categories has been found fort his subcategory. These are the purposive sampling method, basic random assignment sampling method, snowball sampling method and the convenience sampling method with snowball sampling. The purposive sampling method (53 studies, $64.6 \%$ ) was the most preferred sampling method. Basic random assignment (18 studies, $20 \%$ ) was second in order. Then snowball sampling (5 studies, $6.2 \%$ ) and convenience + snowball sampling (2 studies, $2.4 \%$ ) followed. 4 studies (6.8) were coded as missing since they have no relevant information about this criteria.

\section{The Mean Age}

The subcategory corresponded to 8 age intervals. These age intervals are $7-12$ age interval, $18-24$ age interval, $25-30$ age interval, 31 - 36 age interval, 37 - 42 age interval, $43-48$ age interval, 49 - 54 age interval. One of these intervals corresponds to childhood ages $(7-12)$ as the subjects of two studies $(2.4 \%)$ also consisted of children. Another 21 studies $(25.6 \%)$ fell into the $37-42$ age interval. In the 18 - 24 age group, there were $18(22 \%)$ studies and the $31-36$ age intervals was represented by 17 (20.7\%) studies. There were 12 studies (14.6\%) in the 25 - 30 interval while 2 studies $(2.4 \%)$ fell into the $43-48$ age group, 3 studies $(3.7 \%)$ comprised the 49 - 54 interval. In 7 $(8.6 \%)$ studies the mean age criteria could not be found so these studies coded as missing (see Table 1).

Table 1.

Age range of the subjects in the studies.

\begin{tabular}{ccc}
\hline Age Interval & Frequency & Percentile \\
\hline $37-42$ & 21 & 25.6 \\
$18-24$ & 18 & 22.0 \\
$31-36$ & 17 & 20.7 \\
$25-30$ & 12 & 14.6 \\
$49-54$ & 3 & 3.7 \\
$43-48$ & 2 & 2.4 \\
$7-12$ & 2 & 2.4 \\
Missing & 7 & 8.6 \\
Total & 82 & 100.0 \\
\hline
\end{tabular}




\section{The Education Level}

It was coded into 7 subcategories: literate, left primary school, graduated primary school, left high school, graduated high school/university students, left university, and graduated university. For these categories, the most preferable sample is university students with 22 studies; $27.6 \%$ ). The subjects of 25 studies $(30.4 \%)$ were university graduates, while the subjects of 14 studies (17\%) were high school students. The education level of the subjects of 9 studies $(10.4 \%)$ was the graduated primary school. The rate of missing cases was $14.6 \%$ with 12 research studies.

\section{The Gender}

The gender of the subjects in research studies displayed on Figure 2 and Figure 3.

\section{The Sample Size}

8 categories were found fort his subcategory. These categories are $101-200$ subjects, 201 - 300 subjects, $301-400$ subjects, $401-570$ subjects and the studies having big sample sizes. 101 - 200 subjects interval accounted for 33 (38.8\%). The 201 300 groups came in second with 25 studies at $30.9 \%$. The studies having as $301-400$ subjects are $4(7.2 \%)$. In the $401-$ 570 groups there were $14(17.1 \%)$ studies. One study had 1453 $(1.2 \%)$ subjects, and another consisted of 8075 (1.2\%) subjects. Two studies $(2.4 \%)$ comprised 2000 and 1280 subjects. The final study $(1.2 \%)$ was made up of $571-870$ subjects. Therefore, it may be said that most studies fell into the $101-570$ sample interval.

\section{The Marital Status of the Subjects in the Samples}

Of the research studies were found as 52 studies (\%63.4) addressed married subjects, 24 (\%29.4) were for singles, and 2 $(\% 2.4)$ for divorced subjects. The categories not applicable and missing cases were $3(\% 3.6)$ and $1(\% 1.2)$, respectively.

\section{The Duration of the Relationship of the Subjects in the Samples}

It was found that 53 (64.6\%) out of 82 Research Studies (RS) had suitable information, while 29 were identified as either missing (20 studies $24.4 \%$ ) or not applicable ( 9 studies $11 \%$ ).

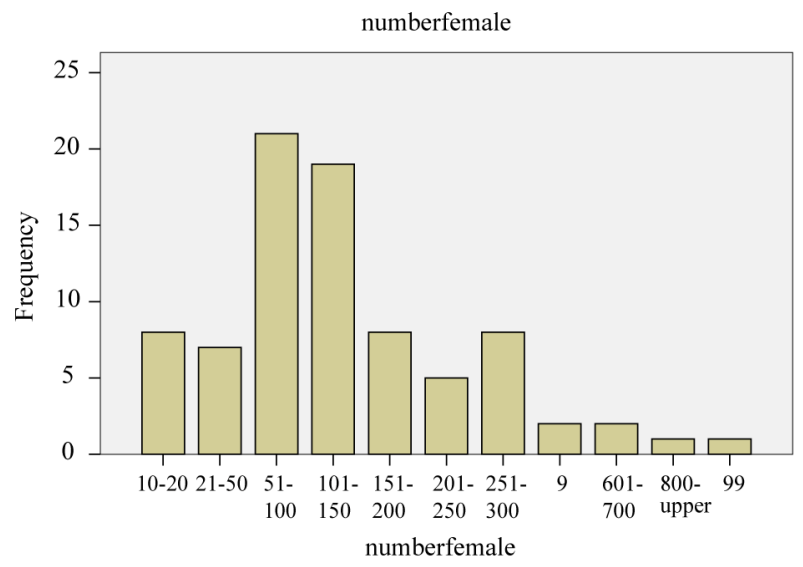

Figure 2.

Female subjects in the research studies.

$10-20$ subjects $151-200$ subjects $\quad 800$-upper subjects

$21-50$ subjects $201-250$ subjects 9 Missing

$51-100$ subjects $251-300$ subjects 99 Not applicable

$101-150$ subjects $601-700$ subjects

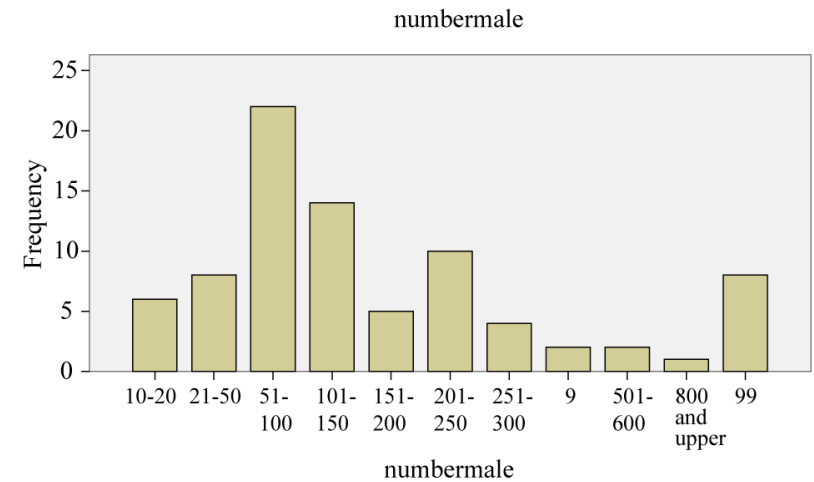

Figure 3.

Male subjects in the research studies.

10 - 20 subjects $151-200$ subjects 800-upper subjects

$21-50$ subjects $201-250$ subjects 9 Missing

$51-100$ subjects $251-300$ subjects 99 Not applicable

101 - 150 subjects $601-700$ subjects

For relationships of 1 - 3 years, 6 studies (7.3\%) were found, 3 (3.6\%) for $1-5$ years, 2 studies $(2.4 \%)$ for 3 years. +1 day to 5 years and 5 studies $(6.1 \%)$ for 5 years. +1 day -7 years. The other durations were: 7 yrs +1 day -9 yrs (6 studies, $7.3 \%), 9+$ 1 day -11 yrs (4 studies, $4.9 \%), 11+1$ day -13 yrs (14 studies, $14.8 \%), 13+1$ day -15 yrs ( 3 studies, $3.6 \%), 15+1$ day -17 yrs ( 2 studies, $2.4 \%$ ), $17+1$ day -19 yrs (4 studies, $4.9 \%), 19+$ 1 day - 25 yrs ( 6 studies, $7.3 \%$ ), and 25 yrs and above ( 2 studies, $2.4 \%)$.

\section{The Living Area of the Subjects of the Samples}

In the all Research Studies $(82,100 \%)$, the analysis indicated that the subjects of 71 studies $(86.6 \%)$ lived in urban areas of Turkey. The 5 studies $(6.1 \%)$ comprised subjects living in rural areas, while the percentage of subjects living in both urban and rural area was $7.3 \%$ for 6 studies.

\section{Researcher Characteristics}

\section{Status of the Researchers}

Out of 82 research studies, 40 (48.8\%) were conducted by professors, assistant professors, associate professors. Then master students follow with 25 (30.5\%) studies. 9 (11\%) RS were conducted by research assistants and specialists at Universities. Only 5 studies $(6.1 \%)$ were done by dissertation students. Only 3 studies (3.6\%) were conducted by professionals working in the area (a psychologist, a doctor and a social worker at different state hospitals).

\section{Gender of the Researchers}

Of the total 82 research studies, 58 studies $(70.7 \%)$ were conducted by female researchers (Figure 2 ). The rest (23 studies $(28.1 \%)$ ) conducted by male professionals (Figure 3 ). The gender of one study's researcher could not be determined as the first name was indicated by initial only so the study $(1,1.2 \%)$ was coded as missing. Thus, it can be said that most research on marriage and relationships has been conducted by lecturers at Turkish universities.

\section{Scale Studies}

Some scales adapted before 1997 were included in this pre- 
liminary report because these were given as a reference in some scale studies done between 1997 and 2008. Among the scale studies, the peak point was the 2001-2002 period (18 studies, \%40.1). 2003-2004 period was second with 9 studies (20.1\%). In 1999-2000, 7 studies (\%15.6) were determined, and 5 studies $(10.9 \%)$ in 1997-1998. In 2005-2008, there were 3 studies $(6.7 \%)$. In $1987-1989$, there were 2 studies $(4.4 \%)$. Only one study $(2.2 \%)$ was found in 1994.

\section{Characteristics of the Scale Studies}

To deal with the studies conducted to adapt a scale or develop a Turkish culturally unique scale, 4 headlines were designed. These are:

\section{Adapted and/or Developed Scales}

Out of 45 studies, it was found that 27 studies $(60 \%)$ had adapted scales from different cultures to Turkish culture and 18 studies $(40 \%)$ developed a scale unique to Turkish culture.

\section{Number of Items of the Scales in the Scale Studies}

All the scales differed in the 4 - 225 items range. 2 studies (4.4\%) had no relevant information so they were coded as missing. There were 11 scale studies $(24.4 \%)$ with 4 - 10 items. The scales having 11 - 20 items were $10(22.4 \%)$. The number of items of the scales being 21 - 36 was 15 (33.3\%). These scales are as follows; 4 scale studies consisting of $151-225$ items $(8.9 \%), 2$ scales $(4.4 \%)$ being in the 151 - 225 range, and 1 scale $(2.2 \%)$ varying between 101 and 150 items were determined.

\section{Construct Validity Measures of the Scale Studies (Factor Structures)}

They were grouped into 4 categories. There were 14 (31.1\%) scales that fell into the $5-10$ factors interval. The number of factors of scales with 1 - 2 factors was $11(24.4 \%)$ Then 9 scales $(20 \%)$ were in the $3-4$ factors interval. 8 scale studies $(17.8 \%)$ had an $11-16$ factor structure. There are three studies $(6.6 \%)$ which have no any relevant information about these criteria so these studies coded as missing.

\section{Reliability Measures of the Scale Studies (Cronbach Alpha Values)}

These categories were divided into 4 intervals. The Cronbach Alpha values in the $90-81$ interval were seen in 24 studies (53.3\%). Another 12 scales had Cronbach Alpha values in the 91 - 96 intervals (26.7\%). There were 8 scales (17.8\%) whose Cronbach Alpha values fell into the $70-80$ intervals. The Cronbach Alpha value of only 1 scale $(2.2 \%)$ was in the $60-69$ intervals.

\section{The Scaling Types of the Scales in the Scale Studies}

A total of 40 scales $(89 \%)$ had varied as likert type points (1 - 3, 1 - 5, 1 - 6, and 1 - 7). The 2 scales (4.4\%) had both yes/no and likert type questions. The other 3 studies $(6.6 \%)$ were in the yes/no subcategory.

\section{“What the Scales in Scale Studies Measures?” (MeasureS)}

This category corresponds to "what the scale in the scale studies measures?". 7 subcategories were determined. The first 22 studies $(48.9 \%)$ dealth with the scales designed for the nature of intimate relationship. The 9 studies $(20 \%)$ were on the

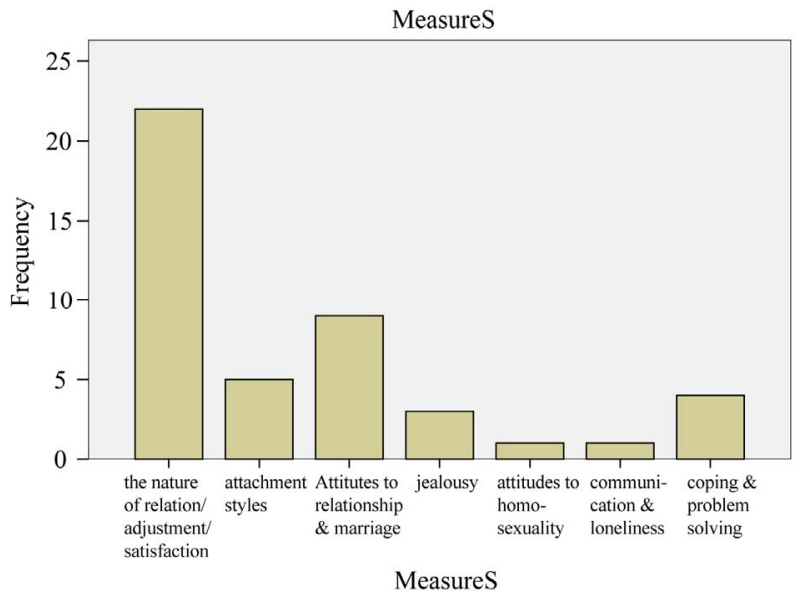

Figure 4.

What the scales measure in Turkish culture. 1) The nature of relationship/adjustment/satisfaction; 2) Attachment styles; 3) Attitudes to relationship \& marriage; 4) Jealousy; 5) Attitudes to homosexuality; 6) Communication \& Loneliness; 7) Coping \& Problem Solving.

people's attitudes to the intimate relationships. The 5 studies $(11.1 \%)$ measured the attachment styles and emotional dependency in both marital and intimate relationships. There were 3 studies (6.7\%) investigating the Jealousy dimension in the intimate studies. One study $(2.2 \%)$ measured the attitudes to homosexuality. However, there comprised 4 studies (8.9\%) for displaying the coping and problem solving strategies for the intimate relationships. Finally, there was only 1 study (2.2\%) on measuring communication and loneliness dimension of the intimate relationships (Figure 4).

\section{Discussion}

In short, this study was conducted to draw an overall picture of the marriage and relationship studies conducted in Turkish culture. According to the results, the studies give the general impression of a well-educated Turkish population living in urban areas. Unfortunately, this situation severely limits the size of the population whose marriage, marital relationships and marital satisfaction were broughtto light. Although there are some studies dealing with other populations, they are very few. This handicap may come from the obligation of using selfreport scales in the studies, which may force the researcher to work with a limited sample. What can be said about the populations constituting a large part of the Turkish community, being poorly educated, living in a rural/urban area, having considerable economical difficulties and suffering from severe marital disfunctions and psychological disturbances resulting from this pathological marital relationship?

With few exceptions, studies on marital and intimate relationships have been conducted in Turkish universities. The subjects of these studies, typically few in number, were from the university population or university graduates living in cities. Some were found to be at least high school graduates, while the population of Turkey consists of many more primary, middle school graduates. In addition Ozkan, Altindag, Oto and Sentunali (2006) indicated that in many rural areas of the country multiple-spouse marriages are somewhat common. Although in 
urban areas there are fewer cases, many marriages are still arranged throughout Turkey. It is widely believed that arranged marriages last longer. There are many cases of severe psychopathological problems seen in women, and fewer in men, who have not married the spouse chosen by the father (Guney et al, 2007). Sayil (1996) claims that the percentage of people attempting suicide in protest is not small. Married couples with any psychopathological problems (Guney et al, 2009) applying to health professionals should first be referred to the preventive psychological and psychiatry clinics to take up the subject of marital relationships. Marriage and relationship studies must have larger subject bases, equal numbers from each educational level to significantly help determine the nature and frequency of psychiatric problems said exist in marriages. Such studies could extend the duration of many marriages. By means of these studies, the psychopathological factors could be addressed. In the development or appearance of psychiatric illnesses, clinicians should remember the partner effect and the actor effect. Since the characteristics of such studies could have important potential effects, it is necessary to improve the technical properties of the studies done in this area. Perhaps protecting the family construct can be seen as a way to prevent psychiatric disturbances that result from living alone. After all, the superior health and contentment of a society consisting of children raised in a happy family environment is common knowledge.

\section{Acknowledgements}

I would like to send my deepest appreciation to Francis A., Macnab, PhD, Founder and Executive Director of Cairnmillar Psychotherapy Institute and Coral Brown, PhD from Cairnmillar Psychotherapy Institute, Melbourne-Australia. I would like to send my special thanks to Tuncay Ergene, $\mathrm{PhD}$ and Zafer Çepni, PhD Student in Hacettepe University, Ankara/ Turkey for their valuable scientific affords and support while conducting this research too.

\section{References}

Brown, C. (2002). The role of attachment in a time-limited marital therapy: Implications for practice and treatment.

Cherlin, A. J. (2003). Marriage, divorce, remarriage. Cambridge, MA: Harvard University Press.

Çepni, Z. (2008). Meta analysis. Unpublished seminar notes. Faculty of Educational Sciences, Hacettepe University, Ankara. Unpublished Dr. Thesis. Melbourne: Australian Catholic University.

Ergene, T. (2003). Effective interventions on test anxiety reduction: A meta-analysis. School PsychologyInternational, 24, 313-328. doi: $10.1177 / 01430343030243004$

Fisiloğlu H., \& Demir A. (2000). Applicability of the dyadic adjust- ment scale of marital quality with Turkish couples. European Journal of Psychological Assessment, 16, 214-218.

Fisiloglu, H., Fowers, J. B., \& Procacci, E. K. (2008). Positive marital illusions and culture: American and Turkish spouses' perceptions of their marriages. Journal of social and personal relationships, 25, 267-285.

Güney, S. (2010). Aile yaşam döngüsü (Family Life Cycle). In T. Solmuş (Ed.), Romantic ilişkiler, evlilik ve ana baba çocuk ilişkileri (romantic relationships, marriage and parent-child communication. An- kara: Nobel.

Güney, S., Macnab, F. A., Sayıl, I., Brown, C. et al. (1998). A study on characteristics of people applying each of the organisations in two different countries for psychological assistance. 34th National Psychiatry Congress, Poster Session, 29 October-3 November, Çeşme İzmir.

Güney, S., Akça, F., Çepni, Z., \& Açıkgöz, S. (2007). Evlilik doyumu ölçeği: bir uyarlama çalışması (index of marital satisfaction: An adaptation study). 4th National Family and Mariage Therapies Conference, Bogazici University, Istanbul.

Güney, S. (1999). The two clients suffering from domestic violence at two different culture. 6th European Conference on Traumatic Stress, Poster Presentation, 5-8 June, Istanbul.

Güney, S., Macnab, F. A., Sayıl, I., Brown, C., et al. (1997). A cross-cultural study of situational crisis and traumatic life events. Victoria: The Victorian State Newsletter.

Hisli, N. (1988). İnsan tek başına (Çeviri: B. H. Raven and J. Z. Rubin, The Person Alone, Social Psychology, 1983). In: N. Bilgin (Ed.), Sosyal psikolojiye giriş (pp. 125-150). İzmir: Ege Üniversitesi Yayinlar1.

Kagitcibasi, C., \& Ataca, B. (2005). Value of children and family chance: A three decade portrait from Turkey. Applied Psychology International Review, 54, 317 .

doi:10.1111/j.1464-0597.2005.00213.x

Kurter, M. F., Jencius, M., \& Duba, J. D. (2004). A Turkish perspective on family therapy: An interview with Hurol Fisiloglu. The Family Journal, 12, 319. doi:10.1177/1066480704264513

Macnab, F. A. (1991). Psychotherapy: New directions for clinical practice. Melbourne: Spectrum Publications.

Macnab, F. A. (1993). Brief psychotherapy: CMT: An integrative approach in clinical practice. Hoboken, NJ: John Wiley \& Sons.

Macnab, F. A. (2000). Traumas of Life (Volume 1). Melbourne: Spectrum Publications.

Macnab, F. A. (2000). Traumas of Life (Volume 2). Melbourne: Spectrum Publications.

Macnab, F. A. (1999). The doctor's case book: Discovering wisdom and contentment. Melbourne: Information Australia.

Sahin, N. H., \& Sahin, N. (1992). How dysfunctional are the dysfunctional attitudes in another culture? British Journal of Psychology Medical Psychology, 65, 17-26. doi:10.1111/j.2044-8341.1992.tb01680.x

Say1l, I. (1996). Kriz ve krize müdahale (crisis and crisis intervention). Ankara: Ankara University Press.

Whisman, M. A., \& Uebelacker, L. A. (2003). Comorbidity of relationship distress and mental and physical health problems. In D. K. Snyder and M. A. Whisman (Eds.), Treating difficult couples: Helping clients with coexisting mental and relationship disorders (pp. 3-26). New York: Guilford Press. 